\title{
Gravity and geoid changes by the 2004 and 2012 Sumatra earthquakes from satellite gravimetry and ocean altimetry
}

\author{
Yusaku Tanaka ${ }^{1, *}, \mathrm{Yao} \mathrm{Yu}^{2,3}$, and Benjamin Fong $\mathrm{Chao}^{3}$ \\ ${ }^{1}$ Earthquake Research Institute, Tokyo University, Tokyo, Japan \\ ${ }^{2}$ School of Geodesy and Geomatics, Wuhan University, Wuhan, China \\ ${ }^{3}$ Institute of Earth Science, Academia Sinica, Taipei City, Taiwan
}

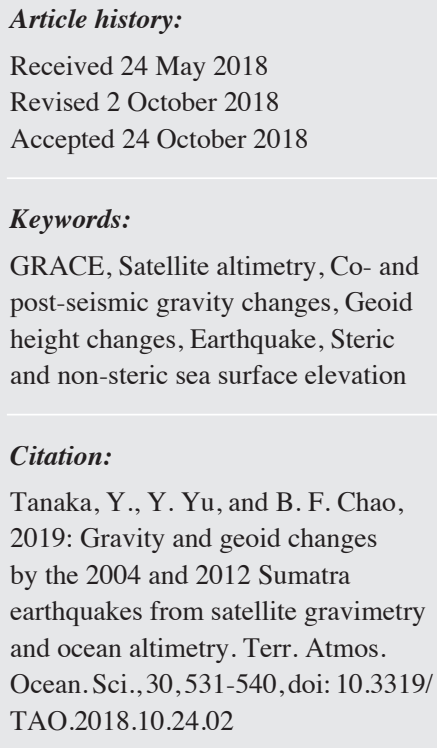

Received 24 May 2018

Revised 2 October 2018

Accepted 24 October 2018

Keywords:

GRACE, Satellite altimetry, Co- and post-seismic gravity changes, Geoid height changes, Earthquake, Steric and non-steric sea surface elevation

Citation:

Tanaka, Y., Y. Yu, and B. F. Chao, 2019: Gravity and geoid changes by the 2004 and 2012 Sumatra earthquakes from satellite gravimetry and ocean altimetry. Terr. Atmos. Ocean. Sci., 30,531-540, doi: 10.3319 / TAO.2018.10.24.02

\begin{abstract}
We first report the results from analyzing the GRACE satellite data for the coseismic and long-term post-seismic changes in the Earth's gravity field and geoid height induced by the 2004 Sumatra-Andaman earthquake (Mw 9.2) and the 2012 Indian-Ocean earthquake ( $\mathrm{Mw}$ 8.6). The results suggest that the two earthquakes have changed the gravity field and geoid height irreversibly (as opposed to cyclically). We next use satellite ocean altimetry measurements to search for the geoid height change induced by the Sumatra-Andaman earthquake, employing an effective method of extracting coherent space-temporal signals, namely the empirical orthogonal functions (EOF) analysis. Our results demonstrate that the sea level variation in the studied (tropical) area during the studied (10-year) period is dominated by the strong steric changes related to ENSO, to the point that the earthquake-induced signals, even using EOF for the largest earthquakes, are obscured and thus undetectable by ocean altimetry. However, this also means that steric and non-steric changes can be observed separately from artificial satellites.
\end{abstract}

\section{INTRODUCTION}

Gravity and geoid height changes induced by large earthquakes before-and-after the event have been reported in the observations of the satellite gravimetry missions of GRACE (Gravity Recovery And Climate Experiment) and GOCE (Gravity Field and Steady-State Ocean Circulation Explorer) as well as ground-based gravimeters. For example, Imanishi et al. (2004) detected coseismic gravity change of the 2003 Tokachi earthquake (Mw 8.3) at a few near-by ground-based gravimeter stations. Han et al. (2006) first detected the coseismic gravity changes by the $2004 \mathrm{Su}-$ matra-Andaman, Indonesia, earthquake ( $\mathrm{Mw}$ 9.2) from the GRACE satellite gravimetry, providing the first two-dimensional satellite observation of coseismic gravity change.

Heki and Matsuo (2010) and Matsuo and Heki (2011) reported the GRACE detection of the coseismic gravity changes of the 2010 Maule, Chile, earthquake (Mw 8.8)

\footnotetext{
* Corresponding author

E-mail:tanaka-u39@eri.u-tokyo.ac.jp
}

and the 2011 Tohoku-oki, Japan, earthquake (Mw 9.0), respectively, and showed that the observation results are well explained by coseismic gravity change models (details are given here in section 2.1). Fuchs et al. (2013) analysed the GOCE satellite and successfully detected coseismic gravity changes by the 2011 Tohoku-oki event. In other examples, coseismic gravity changes of 2012 Indian-ocean earthquake (Mw 8.6) and 2013 Okhotsk deep-focus earthquake (Mw 8.3) are examined by Han et al. (2015) and Tanaka et al. (2015a). Ogawa and Heki (2007) reported that the postseismic gravity increased for some years after the 2004 Sumatra-Andaman event, and Tanaka et al. (2006, 2007, $2015 b$ ) showed the long-term post-seismic gravity increase can stem from viscoelastic relaxation of the upper mantle. Tanaka and Heki (2014) found that the post-seismic gravity changes of the 2004 Sumatra-Andaman, 2010 Maule, and 2011 Tohoku-oki earthquakes have short-term components, which come from afterslips immediately following the main ruptures. These studies have provided new insights into the 
research of the seismic dynamic processes. However, relatively less attention has been paid to the long-term total (co- + post-) seismic gravity field and geoid height changes, which we shall find to be irreversible (as opposed to cyclic as suggested by the notion of earthquake cycles).

In the same vein, irreversible coseismic change in the mean sea surface elevation has been predicted as it would conform to the coseismically changing geoid (e.g., Hayashi et al. 2007), but that has yet to be unequivocally detected. Sladen and Hébert (2008) used satellite altimetry to observe tsunami induced by the 2004 Sumatra-Andaman earthquake, but focused only on the temporal elevations, not on the before-and-after "secular" changes. In this study, we endeavor to search for both seismic gravity changes and sea-level changes related to the geoid height changes in the GRACE and satellite ocean altimetry measurements.

\section{GRAVITY AND GEOID CHANGES FROM GRACE}

\subsection{The Mechanisms of the Gravity Field and Geoid Height Changes by Earthquakes}

The strength of gravitation between two objects is determined by their distance and mass distribution. Therefore, mass re-distributions within the Earth would change the gravity field and geoid height. For example, orogeny can be sensed by GRACE as a local gravity increase because it reflects some form of mass concentration and it alters the distance between the GRACE orbit and a mountain. The magnitude of the gravity anomaly from topography is on the order of $10-100 \mathrm{mGal}\left(\mathrm{Gal}=\mathrm{cm} \mathrm{s}^{-2}\right)$ and that of time-variable gravity from seasonal water movements on the Earth surface is on the order of $1-10 \mu \mathrm{Gal}$ (Syed et al. 2008), about $10^{-9}$ of the standard gravity $\left(9.8 \mathrm{~m} \mathrm{~s}^{-2}\right)$.

The mass re-distribution associated with an earthquake faulting also causes changes in the gravity field and geoid height co- and post-seismically via the mechanisms described as follows [for more details of seismic displacement field induced by earthquakes, see Wang et al. (2012), and for gravity changes see Tanaka (2017)]. Specifically, the coseismic gravity changes are caused by two mechanisms: (1) movement of the boundaries with density contrasts (e.g., the surface or the Moho), and (2) density changes in the crust and mantle. Figure 1a shows the mechanisms of coseismic gravity changes by a thrust-fault earthquake and Fig. 1b ones by a strike-slip earthquake. Additionally, for submarine earthquakes, replacement of sea water with ocean floor elevations also plays a secondary compensating role in changing the

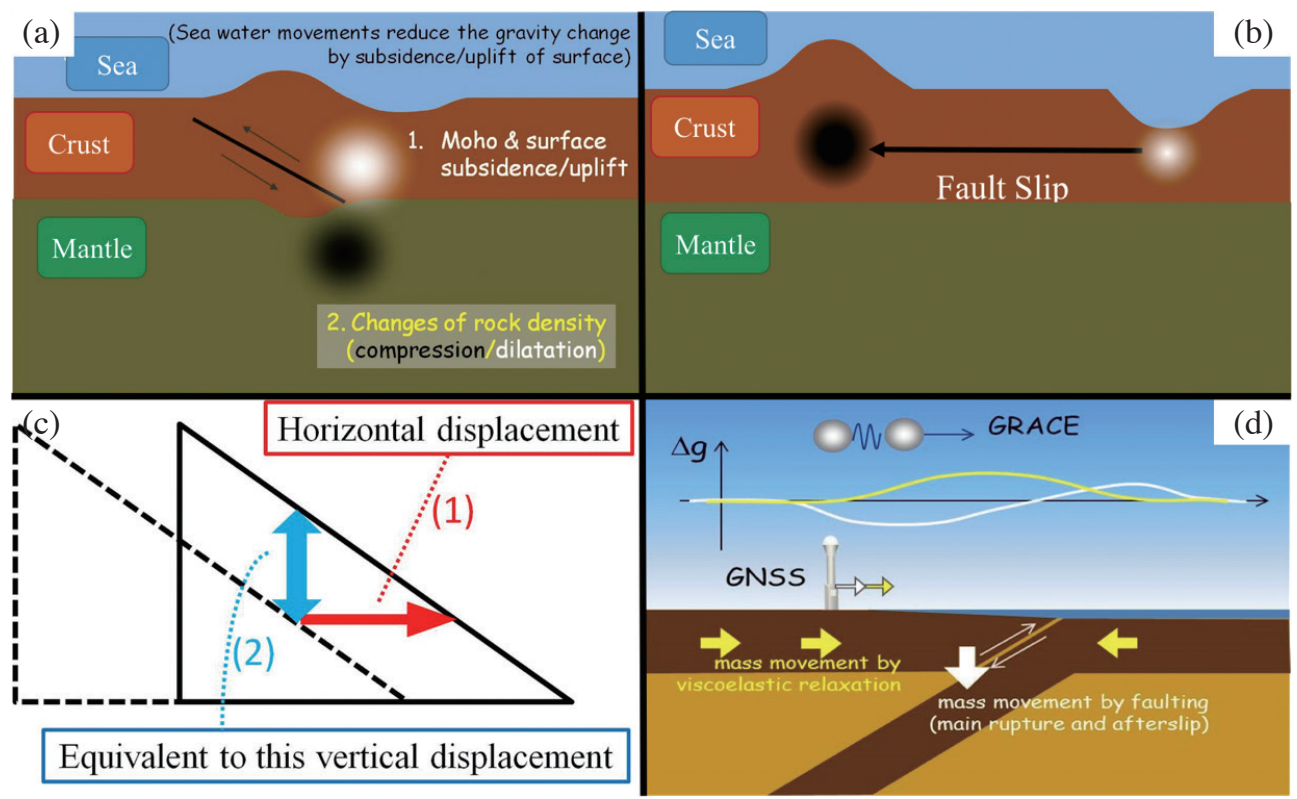

Fig. 1. Schematics to explain the mechanisms of gravity changes due to earthquakes. (a) Mechanisms of coseismic gravity changes by a thrust-fault earthquake [duplicated from Fig. 4.1 of Tanaka (2017)]. (b) Mechanisms of coseismic gravity changes by a strike-slip earthquake. In (a) and (b), the black and white circles respectively indicate the dilatation and compression of the media rock. (c) The mechanism of the gravity changes by horizontal displacements of slant surfaces [duplicated from Fig. 4.2 of Tanaka (2017)]. Horizontal displacements of slant surfaces can change the gravity at specific points of geocentric or geographic coordinate system by changing the distance between the surface of the Earth and the satellite orbit. The horizontal displacements are equivalent to the vertical displacements as shown (c) from the viewpoint of the gravity changes. (d) Mass movements associated with faulting (white arrow) and a Maxwellian viscous relaxation (yellow arrows). This figure is duplicated from Fig. S1 of Tanaka and Heki (2014). The coseismic gravity changes of thrust faults including the afterslip observed by GRACE are characterized by gravity decreasing on the back-arc side mainly reflecting the dilatation and compression. The compression at the lower side and the dilatation at the upper side are equivalent to the downward mass movements shown as the white arrow. Viscous relaxation shown as yellow arrows gathers mass around the faults and increases the gravity taking years to decades. 
gravity. Also, horizontal movements of slant surfaces bring similar effects to the surfaces elevations (Fig. 1c), which, however, are often relatively small (Li et al. 2016).

Secondly, post-seismic gravity changes are supposed to result from the afterslip, visco-elastic relaxation, and poro-elastic rebound of the upper mantle. The afterslips can dominantly change the gravity for the first few months after the main shock, and then give way to the visco-elastic relaxation of the upper mantle which lasts for years to decades. The poro-elastic rebounds have not been observed clearly so far (Tanaka and Heki 2014).

At any rate, the above two post-seismic components are difficult to discriminate with surface velocity measurements because the fore-arc area moves trench-ward in both stages [see Fig. 2 of Wang et al. (2012)]. However, they appear in different polarities in gravity in thrust-fault earthquakes such as the 2004 Sumatra-Andaman event (Fig. 1d). This can be understood as follows: the polarities of the coseismic gravity changes by the main ruptures and the post-seismic gravity changes by the afterslip are the same because the mass redistribution by the afterslip proceeds very similarly to that of the main rupture. They mainly decrease the gravity on the back-arc side (Fig. 2a) (Heki and Matsuo 2010; Matsuo and Heki 2011). On the other hand, visco-elastic relaxation by thrust-fault earthquakes gathers mass under the fault [see Fig. 2 of Wang et al. (2012)], increasing the gravity there. Hence, the polarities of the post-seismic gravity changes by afterslip and visco-elastic relaxation are different for a thrust-fault earthquake. In particular, Fig. 1d depicts the mass movements associated with faulting (white arrow) and a Maxwellian viscous relaxation (yellow arrows). Both of them cause trench-ward movements of GNSS stations on the arc, but GRACE can see the transition from the former to the latter because gravity changes associated with these two

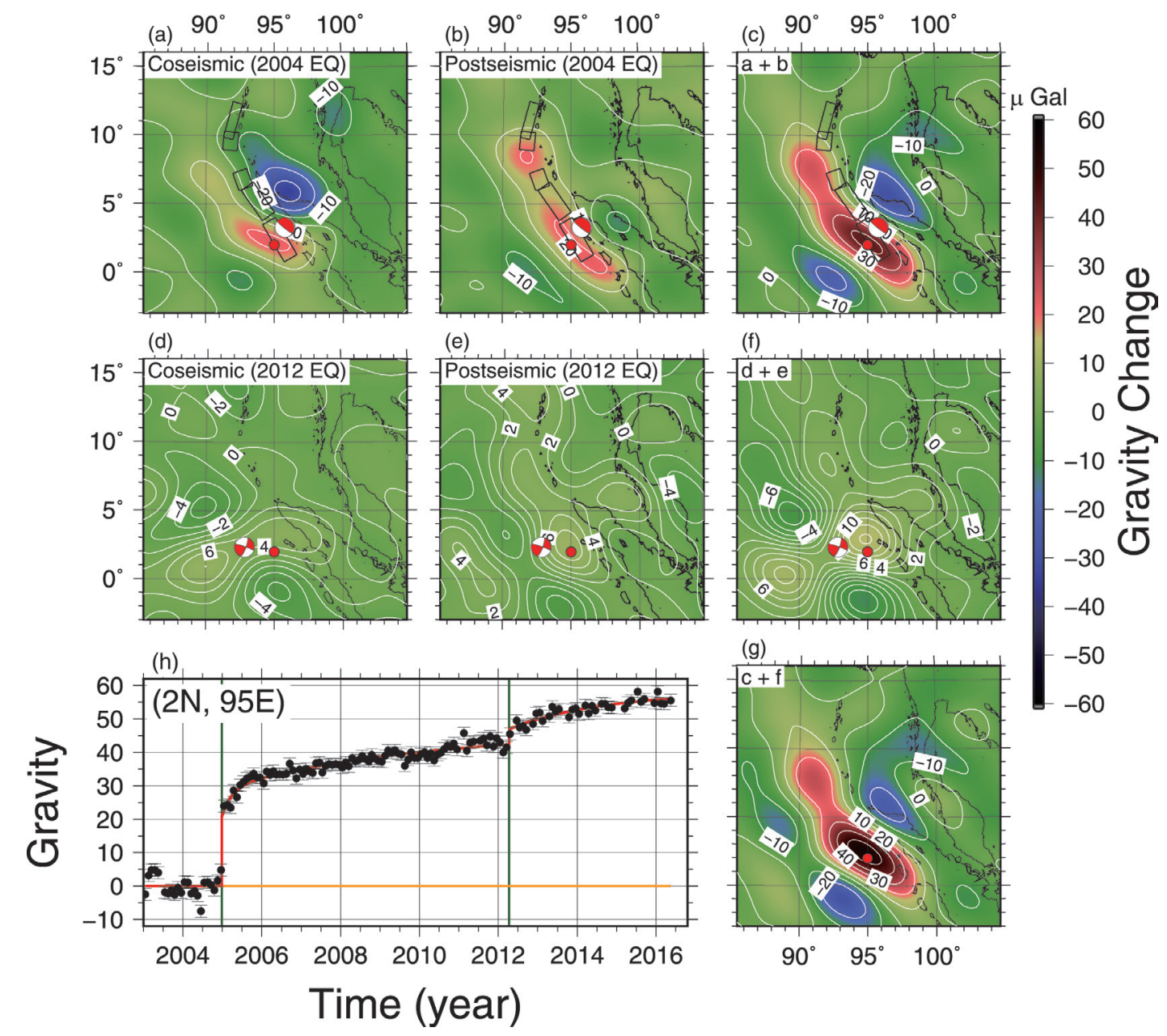

Fig. 2. (a) Coseismic gravity change (in $\mu \mathrm{Gal}$ ) induced by the 2004 Sumatra-Andaman earthquake (its rectangular faults are depicted). (b) The sum of short- and long-term post-seismic gravity changes from the earthquake occurrences till May 2016. (c) The sum of (a) + (b), i.e., co- and postseismic gravity changes. (d), (e), (f) The same as (a), (b), (c) but for the 2012 Sumatra/Indian-Ocean earthquake. (g) The total gravity changes by the two earthquakes. The fault mechanisms of the two earthquakes are shown at the epicenters. (h) The time series of gravity changes $\Delta g$ at the red circles marked in (a) - (g). The overall mean and average seasonal changes have been removed. The black dots with error bars (assumed uniform in time and have been scaled with post-fit residuals) show monthly gravity data and the red curve is the least-squares fit. The two vertical green lines indicates the occurrences of the two earthquakes. 
stages occur in opposite polarities [duplicated from Fig. S1 of Tanaka and Heki (2014)].

However, those of the 2012 strike-slip Sumatra/IndianOcean earthquake have the single polarity (Han et al. 2015) because the visco-elastic relaxation of this kind of earthquake moves mass in a similar way as the main rupture and afterslip. Thus, the spatial pattern of the post-seismic gravity change of the 2012 Indian-Ocean event is different from that of the 2004 Sumatra-Andaman event (Figs. 2b and e).

\subsection{Data and Methods}

To examine the gravity field and geoid height changes, we use the spherical-harmonic Stokes' coefficients complete to degree and order 80 obtained from the RL03-v3 monthly GRACE Level 2 data of Le Centre National d'Études Spatiales (CNES) / Groupe de Recherche de Geodesie Spatiale (GRGS) (Lemoine et al. 2013), available for the period of January 2003 - May 2016. We convert the coefficients into gravity anomaly and geoid height changes following Wahr et al. (1998), and model the resultant, called $\Delta g$, time series at any given location by:

$$
\begin{aligned}
\Delta g(t)= & a_{1}+a_{2} \sin \left(2 \pi t+\theta_{1}\right)+a_{3} \sin \left(4 \pi t+\theta_{2}\right) \\
& +H\left(\Delta t_{s}\right) \times f_{s}\left(\Delta t_{s}\right)+H\left(\Delta t_{i}\right) \times f_{i}\left(\Delta t_{i}\right)
\end{aligned}
$$

where $a_{1}$ is the overall bias, the second and third terms represent annual and semi-annual variations. No linear term is considered because of the limited timespan from the 2002 launch of GRACE to the occurrence of the 2004 SumatraAndaman earthquake, while no a-priori phenomena were known to have caused inter-annual variabilities over our target area. $H$ denotes the Heaviside step function, where $\Delta t_{s}$ and $\Delta t_{i}$ are the time (in year) elapsed since the 2004 Sumatra-Andaman earthquake and the 2012 Indian-Ocean earthquake, respectively. $f_{s}\left(\Delta t_{s}\right)$ and $f_{i}\left(\Delta t_{i}\right)$ denotes the following function of time:

$$
\begin{aligned}
& f_{s}\left(\Delta t_{s}\right)=C_{s}+a_{4}\left\{1-\exp \left(\frac{-\Delta t_{s}}{0.25}\right)\right\}+a_{5}\left\{1-\exp \left(\frac{-\Delta t_{s}}{5.0}\right)\right\} \\
& f_{i}\left(\Delta t_{i}\right)=C_{i}+a_{6}\left\{1-\exp \left(\frac{-\Delta t_{i}}{2.0}\right)\right\}
\end{aligned}
$$

where $C_{s}$ and $C_{i}$ are constants representing coseismic jumps of the two earthquakes, respectively, and the three exponentials time constants, $0.25,5.0$, and 2.0 (years), are estimated by the grid search method. The second and third terms on the right side of Eq. (2) represent respectively the post-seismic gravity field or geoid height changes by the afterslip and the viscoelastic relaxation of the 2004 Sumatra-Andaman earthquake. The second term on the right side of Eq. (3) rep- resents the post-seismic changes of the 2012 Indian-Ocean earthquake. The reason for modeling Eq. (2) with two parameters while (3) with only one parameter is the following. The gravity and geoid changes by afterslip and visco-elastic relaxation of the 2004 Sumatra-Andaman earthquake (thrust fault) have different polarities so that the GRACE observation can separate them (Fig. 1d). On the other hand, those of the 2012 Indian-Ocean earthquake (strike-slip fault) have the same polarity as noted above, so that the GRACE observation can hardly separate them.

\subsection{Results and Discussion}

By applying a least-squares estimation on Eq. (1) for the gravity field and geoid height time series of each grid point (set at $1^{\circ} \times 1^{\circ}$ of longitude and latitude), we map out the coseismic jumps, post-seismic changes and the total changes of the gravity field and geoid height for the period since the occurrence of the 2004 Sumatra-Andaman earthquake to May 2016.

Figures 2 and 3 show respectively the GRACE-observed gravity field changes by the two earthquakes at the spatial resolution of a few hundred $\mathrm{km}$. In all cases the spatial pattern of the sum of the co- and post-seismic, or the total seismic changes (Figs. 2c, f and 3c, f) depicts the overall spatial pattern (Figs. $2 \mathrm{~g}$ and $3 \mathrm{~g}$ ) of decreasing on the back-arc side and on the outer-rise, with increasing along the trench. Judging from the amplitude Figs. $2 \mathrm{~h}$ and $3 \mathrm{~h}$ the post-seismic changes by the two earthquakes have essentially subsided by mid-2016. Figures $2 \mathrm{~g}$, $\mathrm{h}$ and $3 \mathrm{~g}$, $\mathrm{h}$ are the results where the linear trends in the observations are retained (as opposed to being removed) and hence reflect the "true" physical process within the scheme of the plate tectonics. This is the first report on the scenario of the total seismic gravity and geoid height changes, to which less attention has been paid previously. We note that the total seismic gravity changes are irreversible and continue to augment to the co-seismic spatial pattern.

Additionally, the spatial patterns of the co- and postseismic gravity changes of the two earthquakes match well with those from observation and calculation results in previous studies (Han et al. 2015; Tanaka et al. 2015b). They are physically well explained as described in section 2.2, implying that the total changes should also be justified. The difference of the spatial pattern of the coseismic changes between the two earthquakes stem from the difference of the fault mechanisms, namely, the thrust fault for the 2004 Sumatra-Andaman earthquake and the strike-slip fault for the 2012 Indian-Ocean earthquake (Figs. 1a, b).

\section{SEA LEVEL CHANGES FROM SATELLITE ALTIMETRY}

Seeking the minimum gravitational energy, the temporal mean of the sea level in the absence of tides and waves 
conforms to the temporal mean of the geoid. Given that the geoid is changed irreversibly by earthquakes (Fig. 2), a step function in time and a coherent pattern in space should theoretically be able to present the sea level variation (SLV) near the epicenter. With measurement precision on the order of $\mathrm{mm}$ for the geoid and $\mu \mathrm{Gal}$ for the gravity on a large spatial scale, GRACE can actually detect the co- and post-seismic gravity changes induced by much smaller earthquakes than the 2004 Sumatra-Andaman event (Imanishi et al. 2004). On the other hand, the SLV observation by the satellite altimetry is generally within the precision of a few $\mathrm{cm}$. Hence, the SLV occurring in compliance with the geoid height may hopefully be detectable by the satellite altimetry only when the statistics is dealt with properly as feasible.

We use the daily maps of Absolute Dynamic Topography (courtesy of CMEMS) derived from the multi-satellite altimetry reanalysis products (including those from TOPEX/ Poseidon, Jason-1, Jason-2, ENVISAT, GFO, ERS1/2, and Cryosat-2) for the 10-year period of 2000 - 2009 to search for the before-and-after geoid changes induced by the 2004 Sumatra-Andaman earthquake. These ocean altimetry data are given daily on each $0.25^{\circ} \times 0.25^{\circ}$ latitude/longitude grid, with a nominal temporal resolution of better than 10 days.

We first subtract out the Mean Dynamic Topography of the period 1993 - 2012 from these daily maps to obtain the SLV. The SLV, down to cm level precision, sees the combined effects of the mass redistributions detectable by GRACE, plus the steric effect of temperature and salinity changes largely affected by El Niño-Southern Oscillation (ENSO) in the timescale and the tropical area of interest here. We then apply a Gaussian weighted spatial filter with the search window $3^{\circ} \times 6^{\circ}$, and the half-weight scale $1.5^{\circ}$ in latitude and $3^{\circ}$ in longitude to the SLV maps to smooth out the mesoscale footprints, as well as to match the spatial resolution of the filtered SLV to that of GRACE gravity anomaly. We shall adopt the methods of least-squares fit and the empirical orthogonal functions (EOF).

\subsection{Least-Squares Fit}

We apply the least-squares fit-and-subtract procedure with Eq. (1) to the altimetric SLV at each $0.25^{\circ} \times 0.25^{\circ}$ grid

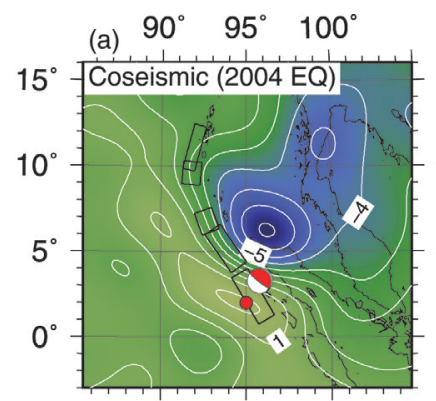

(d)
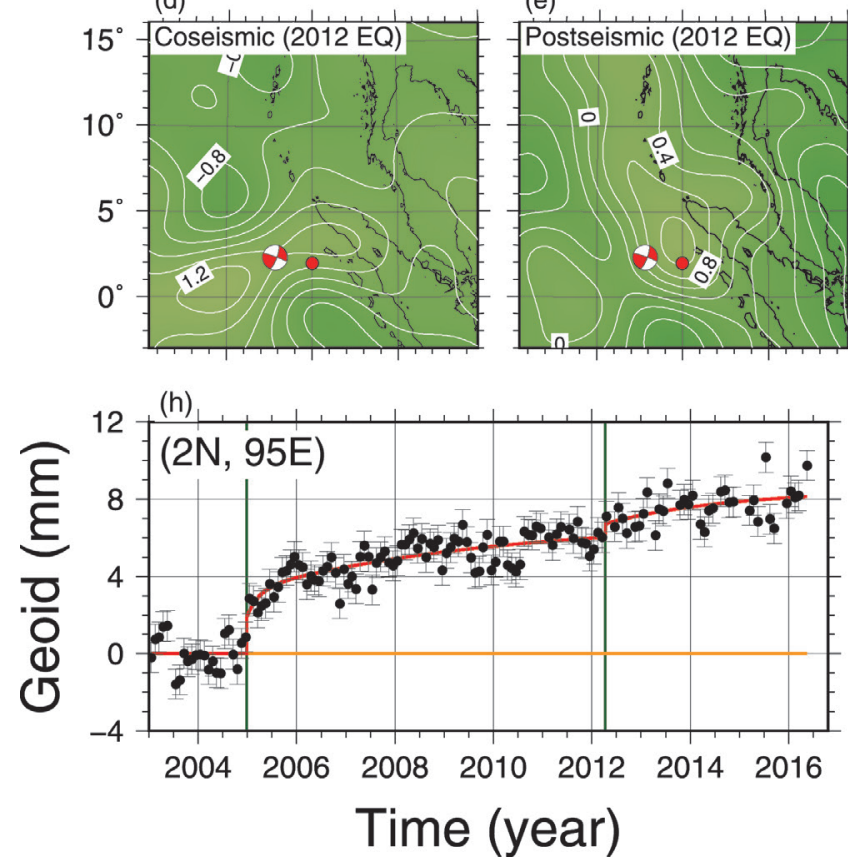

(e)
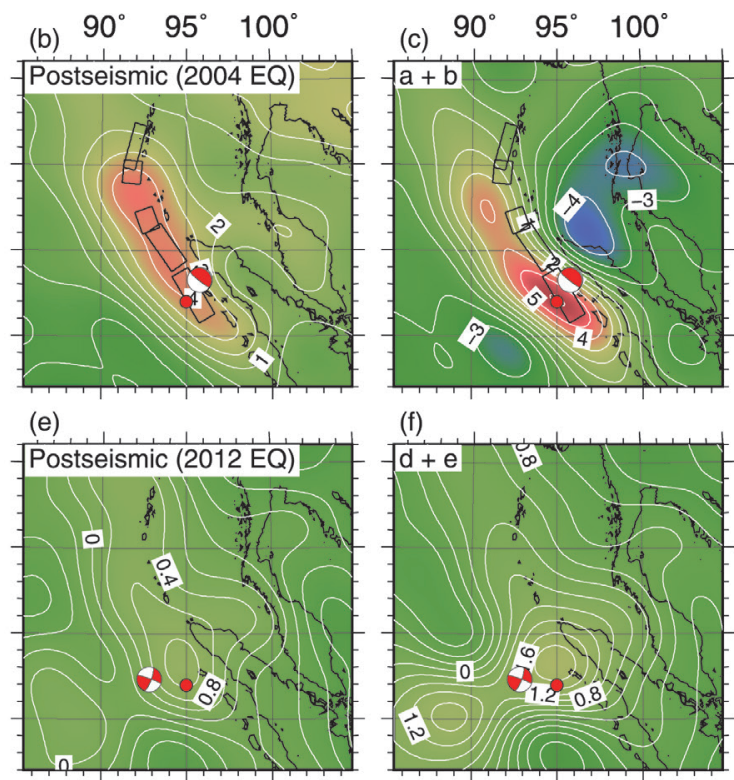

(f)

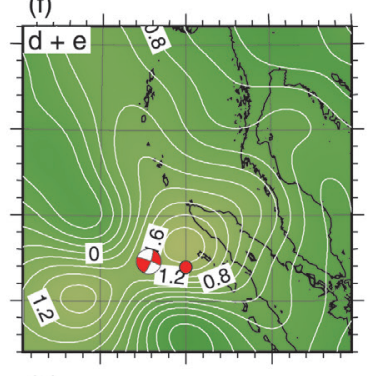

(g)

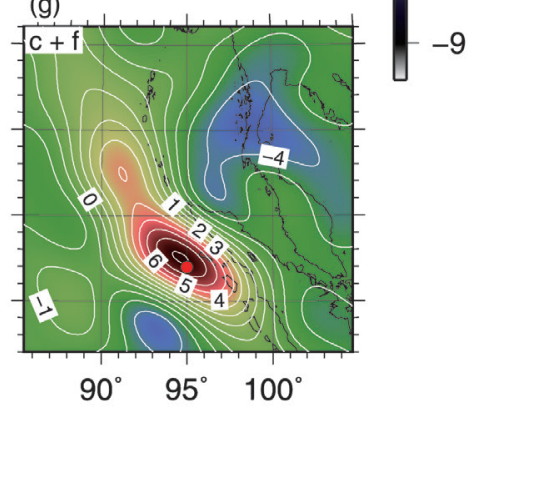

Fig. 3. Same as Fig. 2 but for the geoid height changes. The contour intervals are $1 \mathrm{~mm}$ in (a), (b), (c), (g) and $0.4 \mathrm{~mm}$ in (d), (e), (f). 
point over the period of 2000 - 2009 in search of possible coseismic geoid jumps induced by the 2004 Sumatra-Andaman earthquake. The resultant residual time series retaining the coseismic fit, at the point $\left(11^{\circ} \mathrm{N}, 102^{\circ} \mathrm{E}\right.$, the purple circle in Fig. 4a) in the Gulf of Thailand, is shown as the purple curve in Fig. 4b, over which the least-squares fit is plotted as the black line. We see distinct coseismic drop of the sea level at the earthquake origin time, estimated to be $-4.56 \mathrm{~cm}$. Similarly the results for the nominal epicenter $\left(2^{\circ} \mathrm{N}, 95^{\circ} \mathrm{E}\right.$, the red circle in Fig. 4a) is shown as the bottom red curve in Fig. 4b, where the coseismic sea level drop is estimated to be $-0.14 \mathrm{~cm}$.

Although there is certain correspondence between Fig. 4a and Figs. 1a and c, the above results, however, are believed to be spurious and unrealistic, as the standard deviation for the fit residuals, 6.15 and $5.17 \mathrm{~cm}$ respectively, are larger than the signal detected especially in the second case. The problem evidently resides in the fact that the coseismic signals are relatively weak in the presence of the strong steric SLV related to ENSO in the tropics. More effective tools are called for to possibly extract the coseismic signals from the altimetric SLV.

\subsection{Empirical Orthogonal Function Analysis}

EOF analysis decomposes spatial-temporally coherent signals as orthogonal modes of standing waves (Preisendorfer and Mobley 1988; Hannachi et al. 2007), represented in the form of orthogonal spatial patterns and the associated time series. The spatial pattern shows the relative strength for each grid, and the overall strength of the whole pattern varies in accordance with the time series. The method has been fruitful in studies of coseismic signals in surface GPS deformation from recent earthquakes (Chang and Chao 2014). We first least-squares fit and remove the seasonal signals from the spatially filtered SLV (2000 - 2009) and then feed the residual non-seasonal signals to the EOF analysis. Here the magnitude of the EOF spatial pattern and the corresponding time series are given in such a way that the time series is normalized w.r.t. its standard deviation so that the spatial pattern is left with the actual physical quantity (in unit of $\mathrm{cm}$ in our case).

Figure 5 shows the first three EOF modes, which in order explain 56,22, and $8 \%$ of the total variance. The spatial patterns of EOF-1 and EOF-2 (Figs. 5a and c) show spatially unison oscillation relative to the mean state, one to the west of Sumatra and Malay Peninsula and the other to the east. The time series of EOF-1 as shown in Fig. 5b is evidently highly correlated with the Multivariate ENSO Index (MEI), with a correlation coefficient of 0.37 (far exceeding the $99 \%$ confidence level of 0.13 in the case of our broad-band data of statistical degree of freedom of approximately 360) at time lead of 23 days, suggesting that EOF-1 mainly reflects the steric SLV related to ENSO in the Indian Ocean west of
Sumatra. EOF-2 is also correlated moderately with ENSO (with a correlation coefficient of at 0.24 at time lead of 254 days), yet with more high-frequency variations on account of the complex geography east of Sumatra, where the westward Equatorial Counter Current runs through the South China Sea and Gulf of Thailand. These complex and energetic ocean currents east of Sumatra influence the local steric ENSO-related SLV and generate more high-frequency variabilities. We hold the view that EOF-3 (see Figs. 5d and e) is also an ENSO-related mode as the corresponding time series are also significantly correlated with MEI (with a correlation coefficient of at 0.27 at time lead of 65 days), while the only distinct signal in the spatial pattern of EOF-3 appears around $6^{\circ} \mathrm{N}, 88^{\circ} \mathrm{E}$, which is independent to the spatial features of EOF-1 and EOF-2.

The above analysis demonstrates that ENSO has an apparent influence on the whole analyzed region. We thus try accentuating possible seismic jump signals in SLV by subtracting off the leading EOF mode to reconstruct an "ENSO-free" SLV, and then submit the reconstructed SLV to an EOF analysis focusing on a smaller West Sumatra region. The leading mode (for 2000 - 2009) is shown in Figs. 6a, b. Both the spatial pattern and temporal revolution are similar to Figs. $5 \mathrm{e}$, $\mathrm{f}$, indicating that this mode is still dominated by ENSO even in this smaller area. We then focus on a 1-year time span: $1 / 2+1 / 2$-year before-and-after the earthquake origin time of 2004/12/26. Figures $6 c$ and d suggest the resultant leading EOF mode solution is still much of a repetition of the above 10-year solution, only with shorter time span. Our last try is a 15+15-day solution before-and-after the earthquake; the result of the leading EOF mode is shown in Figs. 6e and f. The spatial pattern of Fig. 6e appears similar to Fig. 3a, still without clear jumps in the time series at the earthquake origin time (Fig. 6f). We thus come to the conclusion that it is unrealistic to hope to detect seismic geoid changes induced by the 2004 Sumatra-Andaman earthquake in the satellite ocean altimetry observations given the satellite configuration at the time.

\section{CONCLUSIONS}

The GRACE satellite captures the co- and post-seismic gravity field and geoid height changes of the 2004 SumatraAndaman earthquake and the 2012 Sumatra/Indian-Ocean earthquake. It has been known that the coseismic gravity changes of a mega-thrust earthquake at a plate boundary as observed by the GRACE satellite are characterized by a gravity decrease on the back-arc side while a post-seismic change by a gravity increase on the trench side. However, it was not clear which of the following scenarios ensues postseismically for mega-thrust earthquakes: whether the total (co- + post-) seismic processes change gravity field and geoid height secularly, or the post-seismic increase acts to partially cancel the coseismic decrease. Our analyses of the 


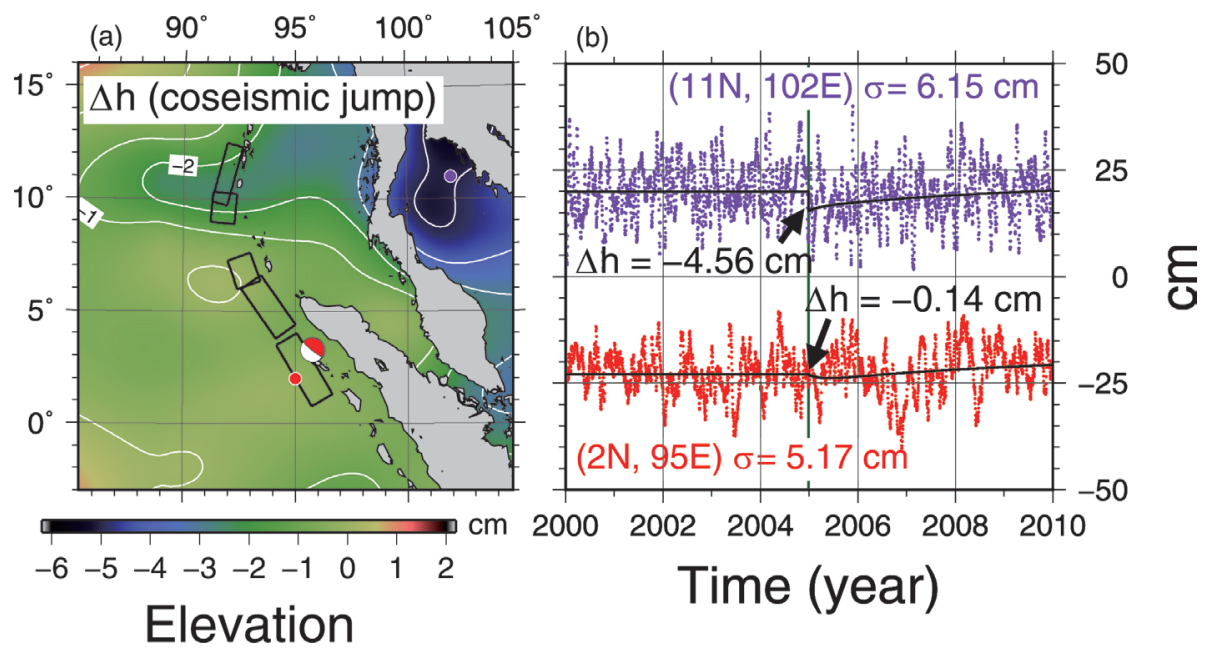

Fig. 4. SLV in unit of $\mathrm{cm}$ induced by the 2004 Sumatra-Andaman earthquake estimated by least-squares fit to altimetry observation. (a) Coseismic sea level jump map (rectangular faults are indicated, the fault mechanisms of the two earthquakes are shown at the epicenters) with the contour interval of $1 \mathrm{~cm}$. (b) The time series of sea level variation at $\left(11^{\circ} \mathrm{N}, 102^{\circ} \mathrm{E}\right)$ [the purple circle in (a)] and the nominal epicenter $\left(2^{\circ} \mathrm{N}, 95^{\circ} \mathrm{E}\right)$ [the red circle in (a)] for 2000 - 2009. Black lines are the fitted coseismic jump curves of Eq. (1) after removing seasonal terms. The green vertical line in (b) labels the earthquake origin time.

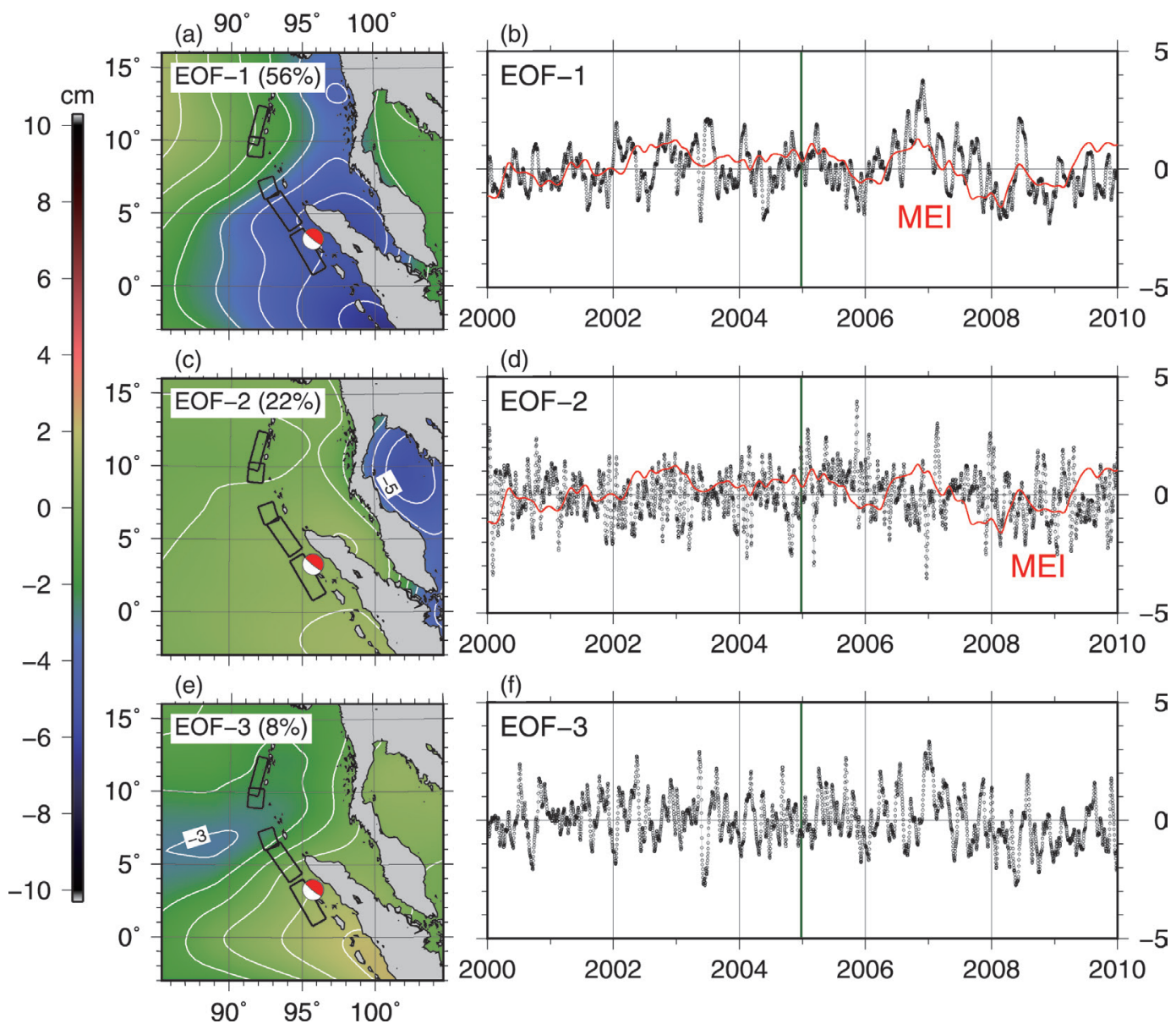

Fig. 5. The first three EOF modes of the non-seasonal SLV for 2000 - 2009. (a) and (b) give respectively the spatial pattern (in unit of $\mathrm{cm}$ ) and the corresponding normalized time series for EOF mode 1; the overlying red line indicates the Multivariate ENSO Index (MEI). (c) and (d) are the same for EOF mode 2; (e) and (f) the same for EOF mode 3. The contour intervals are $1 \mathrm{~cm}$. The green lines in (b), (d), (f) label the origin time of the 2004 Sumatra-Andaman earthquake. 


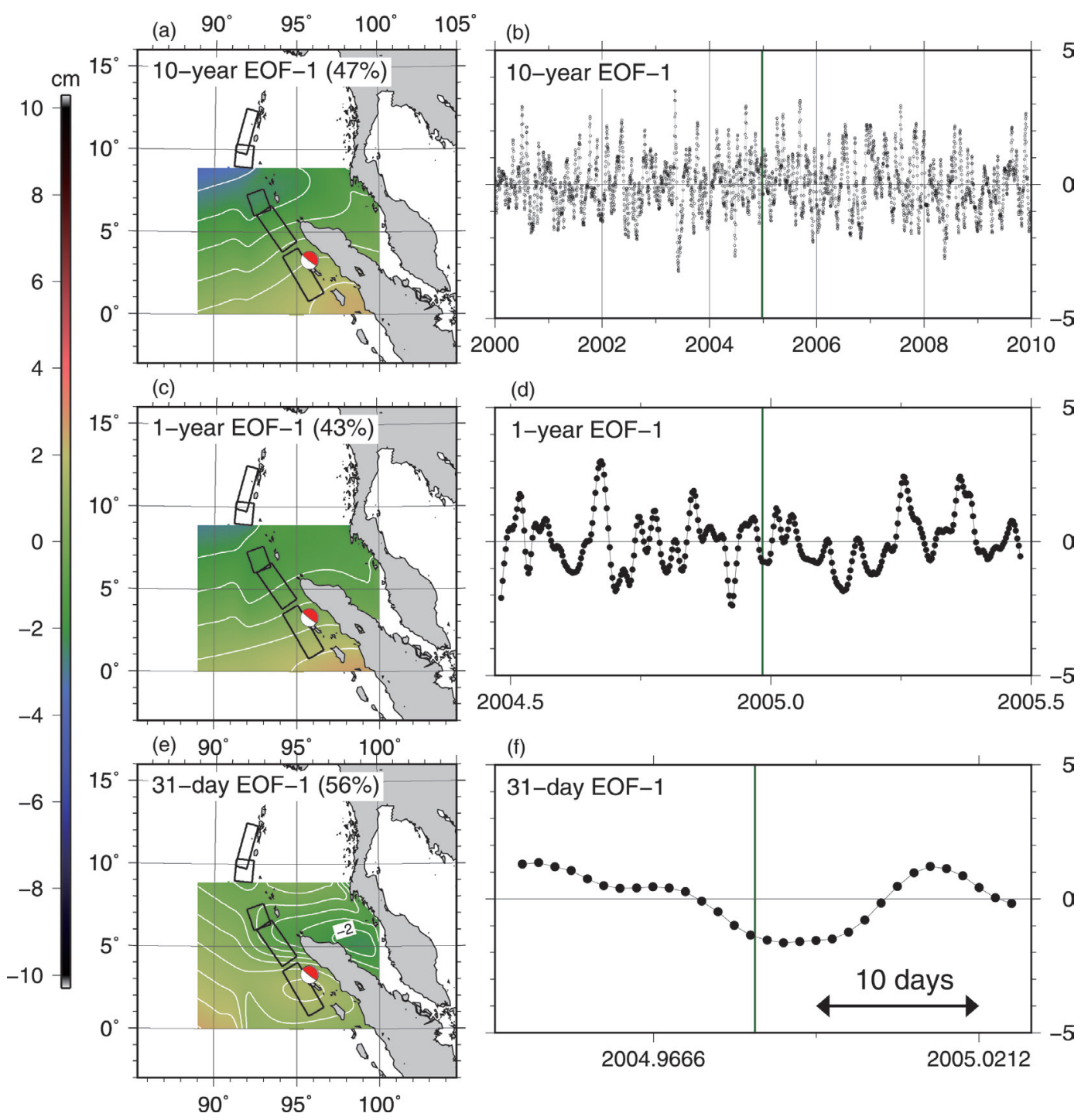

Fig. 6. The leading EOF mode solutions for the designated coloured region of SLV. (a) and (b) for 2000 - 2009 (explaining $47 \%$ of the total variance); (c) and (d) for 1/2 + 1/2 year 2004/6/26 - 2005/6/25 around the origin time of the 2004 Sumatra-Andaman earthquake (explaining 43\% of the total variance); (e) and (f) for 15 + 15 days 2004/12/11 - 2005/1/10 around the origin time (explaining 56\% of the total variance). (a), (c), and (e) are the spatial patterns in the unit of $\mathrm{cm}$ with the contour intervals of $1 \mathrm{~cm}$ in (a) and (c) and $0.5 \mathrm{~cm}$ in (e); (b), (d), and (f) are the normalized time series, where the green lines label the earthquake origin time.

time series of gravity field and geoid height before-and-after the two earthquakes confirm that their co- and post-seismic changes are consistent with the former scenario in the scheme of the plate tectonics; that is, they are irreversible, rather than recovering dictated in the latter scenario. We should emphasize that the total, i.e., co- plus post-seismic gravity changes are irreversible and continue to augment to the co-seismic spatial pattern, as opposed to exhibiting cyclic behaviour as suggested by the notion of earthquake cycles (e.g., Cambiotti et al. 2016).

In terms of the sea level height, the geoid height changes are expected to be present in the non-steric SLV. We have additionally tried various numerical schemes, including the EOF analysis, of optimal extraction of such coherent spatial- temporally signals induced by the 2004 Sumatra-Andaman earthquake in the satellite altimetry data. However, the said non-steric SLV, proven observable from satellite gravimetry as geoid height changes, could not be detected from satellite ocean altimetry in the presence of the much stronger steric SLV. In prospect, one awaits further developments of the atmospheric-oceanic models to become adequate to fully model and to separate out the steric SLV.

Acknowledgements We are grateful to the following organizations for providing the data sets used in this paper: multi-satellite altimetry: http://marine.copernicus.eu/, MEI: https://www.esrl.noaa.gov/psd/enso/mei/table.html, GRACE: http://grgs.obs-mip.fr/grace. This work was 
supported by Grant-in-Aid for JSPS Fellows (16J02130), JSPS KAKENHI Grant Number JP16H06473, and the Taiwan Ministry of Science and Technology grant 106-2116M-001-013. We thank three anonymous reviewers for their constructive comments and the editor Ruey-Juin Rau for the assistance.

\section{REFERENCES}

Cambiotti, G., X. Wang, R. Sabadini, and D. A. Yuen, 2016: Residual polar motion caused by coseismic and interseismic deformations from 1900 to present. Geophys.J.Int., 205, 1165-1179, doi: 10.1093/gji/ggw077. [Link]

Chang, E. T. and B. F. Chao, 2014: Analysis of coseismic deformation using EOF method on dense, continuous GPS data in Taiwan. Tectonophysics, 637, 106-115, doi: 10.1016/j.tecto.2014.09.011. [Link]

Fuchs, M. J., J. Bouman, T. Broerse, P. Visser, and B. Vermeersen, 2013: Observing coseismic gravity change from the Japan Tohoku-Oki 2011 earthquake with GOCE gravity gradiometry. J. Geophys. Res., 118, 5712-5721, doi: 10.1002/jgrb.50381. [Link]

Han, S.-C., C. K. Shum, M. Bevis, C. Ji, and C.-Y. Kuo, 2006: Crustal dilatation observed by GRACE after the 2004 Sumatra-Andaman earthquake. Science, 313, 658-662, doi: 10.1126/science.1128661. [Link]

Han, S.-C., J. Sauber, and F. Pollitz, 2015: Coseismic compression/dilatation and viscoelastic uplift/subsidence following the 2012 Indian Ocean earthquakes quantified from satellite gravity observations. Geophys. Res. Lett., 42, 3764-3772, doi: 10.1002/2015GL063819. [Link]

Hannachi, A., I. T. Jolliffe, and D. B. Stephenson, 2007: Empirical orthogonal functions and related techniques in atmospheric science: A review. Int. J. Climatol., 27, 1119-1152, doi: 10.1002/joc.1499. [Link]

Hayashi, Y., K. Hirata, T. Kuragano, T. Sakurai, H. Takayama, Y. Hasegawa, and N. Hamada, 2007: Feasibility study on the potential of satellite altimetry for detecting seismic geoid changes due to the 2004 SumatraAndaman earthquake. Earth, Planets and Space, 59, 1149-1153, doi: 10.1186/bf03352062. [Link]

Heki, K. and K. Matsuo, 2010: Coseismic gravity changes of the 2010 earthquake in central Chile from satellite gravimetry. Geophys. Res. Lett., 37, L24306, doi: 10.1029/2010GL045335. [Link]

Imanishi, Y., T. Sato, T. Higashi, W. Sun, and S. Okubo, 2004: A network of superconducting gravimeters detects submicrogal coseismic gravity changes. Science, 306, 476-478, doi: 10.1126/science.1101875. [Link]

Lemoine, J.-M., S. Bruinsma, P. Gégout, R. Biancale, and S. Bourgogne, 2013: Release 3 of the GRACE gravity solutions from CNES/GRGS. Geophys. Res. Abstr.,
15, EGU2013-11123.

Li,J.,J.L.Chen, and C.R. Wilson, 2016: Topographic effects on coseismic gravity change for the 2011 Tohoku-Oki earthquake and comparison with GRACE. J. Geophys. Res., 121, 5509-5537, doi: 10.1002/2015jb012407. [Link]

Matsuo, K. and K. Heki, 2011: Coseismic gravity changes of the 2011 Tohoku-Oki earthquake from satellite gravimetry. Geophys. Res. Lett., 38, L00G12, doi: 10.1029/2011GL049018. [Link]

Ogawa, R. and K. Heki, 2007: Slow postseismic recovery of geoid depression formed by the 2004 Sumatra-Andaman earthquake by mantle water diffusion. Geophys. Res. Lett., 34, L06313, doi: 10.1029/2007GL029340. [Link]

Preisendorfer, R. W. and C. D. Mobley, 1988: Principal Component Analysis in Meteorology and Oceanography, Elsevier, Amsterdam/New York, 425 pp.

Sladen, A. and H. Hébert, 2008: On the use of satellite altimetry to infer the earthquake rupture characteristics: Application to the 2004 Sumatra event. Geophys. J. Int., 172,707-714, doi: 10.1111/j.1365-246x.2007.03669.x. [Link]

Syed, T. H., J. S. Famiglietti, M. Rodell, J. Chen, and C. R. Wilson, 2008: Analysis of terrestrial water storage changes from GRACE and GLDAS. Water Resour. Res., 44, W20433, doi: 10.1029/2006WR005779. [Link]

Tanaka, Y., 2017: Geophysical modelings of co- and postseismic gravity changes from satellite gravimetry. Ph.D. Thesis, Hokkaido University, 126 pp, doi: 10.14943/doctoral.k12694. [Link]

Tanaka, Y. and K. Heki, 2014: Long- and short-term postseismic gravity changes of megathrust earthquakes from satellite gravimetry. Geophys. Res. Lett., 41, 5451-5456, doi: 10.1002/2014GL060559. [Link]

Tanaka, Y., J. Okuno, and S. Okubo, 2006: A new method for the computation of global viscoelastic post-seismic deformation in a realistic earth model (I)-vertical displacement and gravity variation. Geophys. J. Int., 164, 273289, doi: 10.1111/j.1365-246X.2005.02821.x. [Link]

Tanaka, Y., J. Okuno, and S. Okubo, 2007: A new method for the computation of global viscoelastic post-seismic deformation in a realistic earth model (II)-horizontal displacement. Geophys. J. Int., 170, 1031-1052, doi: 10.1111/j.1365-246X.2007.03486.x. [Link]

Tanaka, Y., K. Heki, K. Matsuo, and N. V. Shestakov, 2015a: Crustal subsidence observed by GRACE after the 2013 Okhotsk deep-focus earthquake. Geophys. Res. Lett., 42, 3204-3209, doi: 10.1002/2015GL063838. [Link]

Tanaka, Y., T. Hasegawa, H. Tsuruoka, V. Klemann, and Z. Martinec, 2015b: Spectral-finite element approach to post-seismic relaxation in a spherical compressible Earth: Application to gravity changes due to the 2004 
Sumatra-Andaman earthquake. Geophys. J. Int., 200, 299-321, doi: 10.1093/gji/ggu391. [Link]

Wahr, J., M. Molenaar, and F. Bryan, 1998: Time variability of the Earth's gravity field: Hydrological and oceanic effects and their possible detection using
GRACE. J. Geophys. Res., 103, 30205-30229, doi: 10.1029/98jb02844. [Link]

Wang, K., Y. Hu, and J. He, 2012: Deformation cycles of subduction earthquakes in a viscoelastic Earth. Nature, 484, 327-332, doi: 10.1038/nature11032. [Link] 